\title{
Cardiovascular health: a cross-national comparison between the Maine Syracuse Study (Central New York, USA) and ORISCAV-LUX (Luxembourg)
}

\author{
Georgina E Crichton ${ }^{1,2^{*}}$, Merrill F Elias ${ }^{3,4}$, Adam Davey ${ }^{5}$, Nicolas Sauvageot ${ }^{2}$, Charles Delagardelle ${ }^{6}$,
} Jean Beissel ${ }^{6}$ and Ala'a Alkerwi ${ }^{2}$

\begin{abstract}
Background: Cardiovascular disease is the number one cause of death in the United States and in most European countries. Cardiovascular health, as defined by the American Heart Association, is comprised of seven health metrics (smoking, body mass index, physical activity, diet, total cholesterol, blood pressure, and fasting plasma glucose). No studies have compared US data with data collected elsewhere, using this index of cardiovascular health

Methods: We performed comparative analyses of cardiovascular health status in participants from 2 study sites in 2 different countries: the Maine-Syracuse Study, conducted in Central New York, USA in 2001-2006 ( $n=673$ ), and the Observation of Cardiovascular Risk Factors in Luxembourg, conducted in 2007-2009 ( $n=1145$ ).

Results: The Cardiovascular Health Score, the sum of the total number of metrics at ideal levels, was higher in the Luxembourg site than in the Central New York site. Ideal cardiovascular health levels for body mass index, smoking, physical activity, and diet were more prevalent in the Luxembourg site than the Central New York site. Ideal levels for blood pressure were more prevalent in Central New York. Differences between the two sites remained with control for age, gender and socioeconomic indicators.

Conclusions: Cardiovascular health, as indexed by seven health metrics, was higher in the European study site than in the US study site. The largest differences were for the four lifestyle/behavior metrics, namely body mass index, smoking, physical activity, and diet. Preventative and intervention strategies will continue to be important for both countries in order to improve cardiovascular health.
\end{abstract}

Keywords: Cardiovascular disease, Cross-national comparison, Ideal cardiovascular health, Luxembourg, USA

\section{Background}

Cardiovascular disease (CVD) accounts for approximately one of every three deaths in the United States, and is estimated to cost $\$ 312$ billion annually [1]. The American Heart Association (AHA), in its recently released 'Strategic Impact Goal Through 2020 and Beyond' defined levels of four health behaviors (not smoking, engaging in sufficient physical activity, consuming a healthy diet, and body mass index (BMI) less than $25 \mathrm{~kg} / \mathrm{m}^{2}$ ), and three health factors (optimal total cholesterol, blood pressure (BP), and fasting

\footnotetext{
* Correspondence: whige003@mymail.unisa.edu.au

${ }^{1}$ Nutritional Physiology Research Centre, University of South Australia,

Adelaide, Australia

${ }^{2}$ Centre de Recherche Public Santé, Centre d'Etudes en Santé, Strassen,

Grand-Duchy of Luxembourg

Full list of author information is available at the end of the article
}

blood glucose), to identify ideal cardiovascular health [2]. A number of investigators have used this construct and reported low prevalences of ideal cardiovascular health in US samples [3-5]. Furthermore, negative correlations between ideal cardiovascular health and all-cause and CVD mortality $[4,6]$, and cardiovascular events $[4,5,7,8]$ have been identified. Our literature search showed little evidence that attention has been paid to this concept outside of the USA. Moreover, comparisons between the prevalence of poor, intermediate and ideal cardiovascular health levels at study sites in the USA and other countries have not been undertaken.

In order to make a cross-national comparison, we used data collected from two prominent studies with similar data on CVD risk factors, health behaviors, and demographic 
variables: the Maine-Syracuse Longitudinal Study (MSLS) in the United States, and the Observation of Cardiovascular Risk Factors in Luxembourg (ORISCAV-LUX). The MSLS was conducted in Syracuse, New York (NY), USA and its catchment area (Central NY). ORISCAV-LUX was a nation-wide, population-based study. Several considerations make these specific comparisons important and meaningful. First, existing multinational data collection efforts (e.g., Health and Retirement Study in the USA/Survey of Health, Ageing and Retirement in Europe) do not measure key aspects of cardiovascular health (e.g., diet, total cholesterol, $\mathrm{BP})$ and we know of no nationally representative data set that permit comparisons on these indices. Second, the MSLS and ORISCAV-LUX collect measures in essentially identical fashions, and both samples are representative of their respective geographic areas. Data collected from Luxembourg are of particular interest due to the multinational nature of its population, with a large number of individuals originating from neighboring European countries living in Luxembourg. As in the US, CVD is the number one cause of mortality in Luxembourg, with CVD related illnesses accounting for 33.8\% of all deaths in 2011 [9].

Our overall objective was to compare the pattern of cardiovascular health between two geographically and culturally distinct sites in the US and in Luxembourg. Specifically, the first objective was to compare the sites with respect to the total number of health metrics at ideal levels, indexed by a global Cardiovascular Health Score (CHS), derived from the AHA construct of cardiovascular health. The second objective was to examine the prevalence of poor, intermediate, and ideal health for each health behavior (smoking, physical activity, diet, BMI), and health factor (total cholesterol, BP, and fasting blood glucose) at each site. The third objective was to assess whether any observed differences in the cardiovascular health components between the two study sites remained after controlling for socioeconomic indicators. As European countries have higher rates of walking, cycling, and active transportation than in the United States [10], and a number of studies have shown an inverse association between active transportation and overweight/obesity, BP, and triglyceride and fasting insulin levels [10-15], we hypothesised that the CHS would be higher in the Luxembourg site than in the Central NY site. With regard to the individual health metrics, we postulated that the prevalence of ideal levels for physical activity and BMI would also be higher in Luxembourg than Central NY.

\section{Methods}

\section{Participants in MSLS (USA)}

The MSLS is a community-based study of aging, cardiovascular risk factors and cognitive functioning in adults, aged 23-98 years [16-19]. At initial recruitment, the sole exclusions were institutionalized people, diagnosed alcoholism and psychiatric disorder. The data for the present study were taken from subjects returning for the 6th (2001-2006) study wave when dietary intake measures were first obtained. At this time, $80.7 \%$ of participants were residing in Onondaga County and $10.1 \%$ in 3 counties surrounding Onondaga County in the Central NY area of upstate New York State. The remaining original residents of Central NY (9.2\%) had relocated to 1 of 15 different states at the time this study was conducted. Demographics and health statistics published for Onondaga County, NY, best describe this sample [20]. Beginning with a sample of 1049 individuals, participants were excluded from the present analysis for the following reasons: missing dietary or cardiovascular health data $(\mathrm{n}=34)$, acute stroke $(n=28)$, probable dementia $(n=8)$, hemo-dialysis $(n=5)$, inability to read English $(\mathrm{n}=1)$, and alcohol abuse after baseline $(n=1)$, leaving 972 participants.

\section{Participants in ORISCAV-LUX (Luxembourg)}

ORISCAV-LUX, a nationwide, cross-sectional study conducted in 2007-2009, was designed to gather information on the prevalence of cardiovascular risk factors among the adult population of Luxembourg. Exclusions were institutionalized people $(n=12)$, pregnancy $(n=21)$, serious mental and/or physical handicap $(\mathrm{n}=5)$, prisoners $(\mathrm{n}=1)$, people outside the determined age range $(n=2)$ and those deceased before recruitment $(n=5)$ [21]. A representative random sample of 1432 individuals, stratified by sex, age (18-69 years) and district of residence completed the recruitment procedure $[21,22]$. After eliminating those with missing data on components of cardiovascular health, data were available for 1352 of the ORISCAV-LUX sample.

\section{Final comparative sample}

In both studies only participants aged 30-69 were included in order to compare two age-homogeneous samples. The final sample comprised 1818 individuals (673 from MSLS and 1145 from ORISCAV-LUX). Further details related to the methods of sampling for both studies appear elsewhere $[18,19,21,22]$. All participants gave informed written consent to take part. The MSLS was approved by the University of Maine Institutional Review Board and ORISCAV-LUX by the National Research Ethics Committee and the National Commission for Private Data Protection.

\section{Procedure}

\section{Cardiovascular health metrics}

Participants at both study sites underwent physical and anthropometric measurements, blood tests, and completed self-administered questionnaires to gain information on demographic and socioeconomic characteristics. Standardized protocols for data collection were used. 
Body weight, height, BMI and BP measures were assessed as described previously for both studies [16,18,19,21-23]. Standard assay methods were employed [18,23] to obtain fasting plasma glucose $(\mathrm{mg} / \mathrm{dl})$ and total cholesterol $(\mathrm{mg} / \mathrm{dl})$.

In the MSLS, physical activity was measured with the Nurses' Health Study (NHS) Activity Questionnaire [24]. Dietary intake was assessed using the food frequency questionnaire (FFQ) component of the Nutrition and Health Questionnaire [25]. Smoking status was based on self-report from the same questionnaire [25]. At the conclusion of each wave, MSLS subjects were informed of any new risk factors detected at that examination and advised to consult their physician for treatment.

In ORISCAV-LUX, physical activity was measured using the short format International Physical Activity Questionnaire (IPAQ) [26]. Detailed data regarding smoking were obtained from the health questionnaire. Dietary intake was assessed using a semi-quantified FFQ assessing the frequency of consumption of 134 items [27]. All questionnaires used in ORISCAV-LUX were available in French, English, German, and Portuguese. ORISCAV-LUX subjects were advised to see their physicians for treatment if any cardiovascular anomaly was detected during the study assessment.

\section{Diet metric}

For the diet metric, two food scores were calculated for each study, a Recommended Food Score (RFS) [28], and a non-Recommended Food Score (non-RFS) [29]. These scores were used according to the availability of dietary data in order to capture a detailed measure of dietary intakes. The RFS comprised 18 food items, based on the recommendations of the 2010 Dietary Guidelines for Americans [30]. One point was awarded for consumption of any of the recommended foods at least once per week (fruit, vegetables, legumes, wholegrain cereal products, low fat dairy products, fish, nuts), otherwise 0 points were given [28], to give a total score out of 18. Included foods were similar to those used previously $[28,31,32]$.

The non-RFS [29] included 13 items that are recommended to reduce [30], including processed meats, refined grains, solid fats, added sugars, and alcohol. Consumption of non-recommended foods at least two to four times per week was assigned a score of 1 ; otherwise 0 points were assigned [31,33]. A total non-RFS out of 13 was calculated, with a higher value indicating a higher consumption of non-recommended food items.

\section{Cardiovascular health score}

Poor, intermediate, and ideal health levels for smoking, BMI, physical activity, total cholesterol, BP, and fasting plasma glucose were calculated using the AHA definitions [2] (see Online Resource 1). For the RFS, scores of
$0-7,8-11$, and $12-18$ were defined as poor, intermediate, and ideal, respectively. Scores of 5-13, 3-4, and 0-2 for the non-RFS were defined as poor, intermediate, and ideal.

The CHS comprised the sum of components at ideal levels, ranging from 0 (no cardiovascular health components at ideal levels) to 8 (all cardiovascular health components at ideal levels). This global score was then categorized into low (0-2 components at ideal levels), medium (3-5) or high (6-8).

\section{Data analysis}

According to the type of variable (continuous or categorical), independent samples t-tests and Chi-square tests were used to compare demographic variables, mean scores of the cardiovascular health metrics and other health variables in the two samples $(n=673$ for MSLS, $\mathrm{n}=1145$ for ORISCAV-LUX).

The proportion of each sample in the poor, intermediate and ideal categories for each cardiovascular health metric were calculated. As prevalence estimates are strongly gender and age-dependent (e.g., risks increase for chronic diseases with age), prevalence comparisons between populations may be misleading if the underlying age and/or gender composition differs in the populations being compared [34]. To overcome this, direct gender and age standardization according to the Segi world standard population was used to compute gender and age standardized prevalence in each health category [35].

Prevalence of each health category (e.g., poor health) for each health metric in the two study sites were compared by computing the comparative morbidity ratio and testing it for statistical significance [36]. This was also performed for the global CHS (comparing low, medium and high categories between the two sites).

General linear models were used to examine associations between study site and each cardiovascular health component (as continuous variables). Statistical adjustment was made for age, gender, education and income. Interactions of study site with gender and age were not significant. SPSS version 21 and SAS (version 6.1) were used for all analyses. P values of $<0.05$ were considered statistically significant.

Sensitivity analyses were performed excluding the minority populations in each sample $(\mathrm{n}=52$ in ORISCAVLUX and $n=65$ in MSLS) and excluding the persons residing in states other than NY at the time of wave 6 MSLS (10\%). The results were unchanged (data not shown).

\section{Results}

\section{Descriptive data}

Table 1 shows the demographic, cardiovascular health components, and other health variables for MSLS and 
ORISCAV-LUX participants. The MSLS sample had a higher proportion of participants who were obese, had diagnosed hypertension, diabetes, or CVD (all $\mathrm{p}<0.001$ ), compared with the Luxembourg sample. The proportion of those treated for diagnosed hypertension was significantly higher at the Central NY site (84.3\%) than in Luxembourg $(37.7 \%)(\mathrm{p}<0.001)$.

\section{Cardiovascular health Health behaviors}

As shown in Table 1, BMI was significantly higher in the Central NY sample than in the Luxembourg sample $(\mathrm{p}<0.001)$. The dietary measures indicated a lower intake of recommended foods and a higher intake of non-recommended foods at the Central NY site compared with intakes at the Luxembourg site (both $\mathrm{p}<0.001$ ). Cigarettes smoked per day and time spent engaging in weekly physical activity were both higher at the Luxembourg site than at the Central NY site (both $\mathrm{p}<0.01$ ).

The observed differences in BMI, physical activity and diet (RFS and non-RFS) remained statistically significant with the additional adjustment for age, gender, education, and income (all p < 0.001) (Table 2). Weekly physical activity time was over two times higher in the Luxembourg sample than in the Central NY sample. This difference remained significant in secondary analyses with statistical adjustment for BMI, waist circumference and waist/hip ratio (data not shown).

\section{Health factors}

Fasting plasma glucose was significantly higher in the Central NY sample than in the Luxembourg sample $(\mathrm{p}<$ 0.001 ), while mean systolic and diastolic BP were both significantly higher in Luxembourg (both $\mathrm{p}<0.001$ ) (Table 1 ). $\mathrm{BP}$ measures, as well as total cholesterol were significantly higher in Luxembourg than in the Central NY site when adjusted for age, gender, education, and income (Table 2). The BP difference was unchanged with statistical adjustment for BMI, waist circumference and waist/hip ratio (data not shown).

\section{Total cardiovascular health score}

The mean total CHS (number of metrics at ideal levels) was significantly higher at the Luxembourg site (4.2) than at the Central NY site (3.8) (fully adjusted model, Table 2, $\mathrm{p}<0.001$ ). The proportion of the sample with overall ideal health' ( $8 / 8$ components at ideal levels) was $1.0 \%$ at the Luxembourg site, compared with $0.4 \%$ at the Central NY site (not statistically significant).

\section{Poor, intermediate and ideal cardiovascular health comparison}

The percentages of participants in ORISCAV-LUX and MSLS with poor, intermediate and ideal health for each health behavior and factor, and the global CHS (age and gender standardized) are shown in Table 3. The percentage of those with ideal health was significantly higher in the Luxembourg site than in the Central NY site for BMI, smoking, physical activity and diet (both scores) (all $\mathrm{p}<0.01$ ). The percentage of those with ideal BP levels was higher in the Central NY site than in the Luxembourg site $(\mathrm{p}<0.001)$.

Poor health levels for BMI and diet (RFS and nonRFS) were statistically significantly higher at the Central NY site than at the Luxembourg site (all $\mathrm{p}<0.05$ ). Prevalence of poor levels for BP and total cholesterol were higher in Luxembourg than in Central NY (both $\mathrm{p}<0.001$ ).

Figure 1 shows the proportion of participants in each site (aged 30-69 years) with a low (0-2 health components at ideal levels), medium (3-5 health components at ideal levels), and high (6-8 health components at ideal levels) CHS. A greater percentage of participants in the Luxembourg site had a higher number of total health components in the high category (CHS 6-8), than in the Central NY site $(\mathrm{p}<0.05)$.

\section{Discussion}

The present study is, to our knowledge, the first to make cross-national comparisons using the AHA-defined components of cardiovascular health. Although we are unable to generalize beyond the two geographic study sites in Central NY, USA and Luxembourg, the study provides insight into how cardiovascular health differs between two sites in the US and Europe. Luxembourg, a centrally located European country with a large proportion of the population coming from Portugal and neighboring countries including Belgium, Germany and France, serves as a good representation of western Europe. Syracuse and its surrounding counties are ethnically diverse, and constitute the economic and educational hub of Central NY state.

The overall CHS, generated from the individual health metrics, was higher at the Luxembourg site than at the Central NY site. Ideal levels for BMI, smoking, physical activity, and diet were more prevalent in Luxembourg than in Central NY. However, ideal levels for BP were more prevalent in Central NY. Differences between the two sites with respect to BMI, physical activity, diet and $\mathrm{BP}$ cannot be attributed to age, gender, income and education as findings remained after adjustment for these potential confounders.

Importantly, the prevalence of overall ideal cardiovascular health (ideal levels for all components) was low at both the Central NY site (0.4\%) and the Luxembourg site $(1.0 \%)$. This is consistent with smaller state-based studies and national data in the USA, with prevalences ranging from $0-0.1 \%[1,3,5]$ to $1.2 \%$ [4]. Of concern are the national (US) data indicating that the prevalence of ideal cardiovascular health decreased from $2.0 \%$ in $1988-1994$ 
Table 1 Demographic, cardiovascular and health variables for MSLS $(n=673)$ and ORISCAV-LUX $(n=1145)$ participants

\begin{tabular}{|c|c|c|c|c|c|}
\hline \multirow[t]{2}{*}{ Variable } & \multicolumn{2}{|c|}{ Central New York MSLS } & \multicolumn{2}{|c|}{ Luxembourg ORISCAV-LUX } & \multirow[t]{2}{*}{ p-value } \\
\hline & $\mathrm{M}$ or $\%$ & SD & $\mathrm{M}$ or $\%$ & SD & \\
\hline Age, yrs & 55.5 & 8.7 & 47.9 & 10.7 & $<0.001$ \\
\hline Gender & & & & & 0.001 \\
\hline Males & 41.0 & & 48.8 & & \\
\hline Females & 59.0 & & 51.2 & & \\
\hline Education & & & & & $<0.001$ \\
\hline Primary & 5.4 & & 26.8 & & \\
\hline Secondary & 40.1 & & 46.7 & & \\
\hline Tertiary & 54.5 & & 26.5 & & \\
\hline Income ${ }^{1}$ & & & & & $<0.001$ \\
\hline Q1 (<30 000) & 23.8 & & 17.8 & & \\
\hline Q2 (30 000 to 60000$)$ & 37.6 & & 51.0 & & \\
\hline Q3 (60 000-120 000) & 35.3 & & 25.8 & & \\
\hline Q4 (>120 000) & 3.3 & & 5.4 & & \\
\hline Race & & & & & $<0.001$ \\
\hline Caucasian & 90.3 & & 95.5 & & \\
\hline Other & 9.7 & & 4.5 & & \\
\hline \multicolumn{6}{|l|}{ Cardiovascular Health metrics } \\
\hline Smoking, no cigarettes per day (all) & 1.7 & 5.7 & 2.7 & 7.2 & 0.002 \\
\hline Smoking, no cigarettes per day (smokers) & 13.0 & 10.2 & 14.6 & 10.3 & 0.23 \\
\hline $\mathrm{BMI}, \mathrm{kg} / \mathrm{m}^{2}$ & 29.9 & 6.3 & 27.1 & 4.9 & $<0.001$ \\
\hline Physical activity, mins/wk ${ }^{2}$ & 273 & 345 & 778 & 936 & $<0.001$ \\
\hline Total cholesterol, mg/dl & 203.6 & 39.8 & 206.3 & 39.7 & 0.17 \\
\hline Systolic BP, mm Hg & 126.8 & 20.7 & 131.6 & 18.2 & $<0.001$ \\
\hline Diastolic BP, mm Hg & 70.8 & 10.2 & 83.8 & 10.9 & $<0.001$ \\
\hline Fasting blood glucose, mg/dl & 98.4 & 28.9 & 94.5 & 18.6 & $<0.001$ \\
\hline RFS, $0-18^{3}$ & 9.2 & 2.8 & 10.8 & 2.8 & $<0.001$ \\
\hline non-RFS, $0-13^{4}$ & 3.3 & 1.6 & 3.0 & 1.6 & $<0.001$ \\
\hline Total CHS, 0-8 & 3.8 & 1.6 & 4.2 & 1.6 & $<0.001$ \\
\hline Proportion of sample with $\mathrm{CHS} 0 / 8$ & 0.7 & & 0.3 & & 0.25 \\
\hline Proportion of sample with $\mathrm{CHS} 8 / 8$ & 0.4 & & 1.0 & & 0.17 \\
\hline \multicolumn{6}{|l|}{ Other health measures } \\
\hline Height, cm & 168.7 & 9.8 & 169.4 & 9.8 & 0.13 \\
\hline Weight, kg & 85.3 & 20.2 & 78.1 & 16.5 & $<0.001$ \\
\hline Waist circumference, $\mathrm{cm}$ & 95.6 & 15.6 & 91.4 & 13.5 & $<0.001$ \\
\hline Hip circumference, $\mathrm{cm}$ & 109.2 & 12.5 & 101.6 & 9.5 & $<0.001$ \\
\hline Waist:hip & 0.87 & 0.09 & 0.90 & 0.09 & $<0.001$ \\
\hline $\mathrm{CRP}, \mathrm{mg} / \mathrm{dL}$ & 0.41 & 0.46 & 0.27 & 0.48 & $<0.001$ \\
\hline Alcohol intake, standard drinks/d & 0.5 & 1.0 & 1.3 & 1.3 & $<0.001$ \\
\hline Obese, BMI $\geq 30 \mathrm{~kg} / \mathrm{m}^{2}$ & 42.1 & & 25.5 & & $<0.001$ \\
\hline Diabetes $^{5}$ & 10.7 & & 5.8 & & $<0.001$ \\
\hline Treated participants with diabetes & 79.2 & & 65.2 & & 0.07 \\
\hline Treated diabetes: fasting blood glucose, mg/dl & 156.3 & 65.3 & 152.7 & 45.4 & 0.76 \\
\hline Untreated diabetes: fasting blood glucose, mg/dl & 143.7 & 21.3 & 138.4 & 15.1 & 0.37 \\
\hline
\end{tabular}


Table 1 Demographic, cardiovascular and health variables for MSLS $(n=673)$ and ORISCAV-LUX $(n=1145)$ participants (Continued)

\begin{tabular}{|c|c|c|c|c|c|}
\hline Hypertension $^{6}$ & 54.8 & & 43.3 & & $<0.001$ \\
\hline Treated participants with hypertension & 84.3 & & 37.7 & & $<0.001$ \\
\hline Treated hypertension: systolic BP, mm Hg & 134.4 & 20.1 & 145.4 & 18.7 & $<0.001$ \\
\hline Treated hypertension: diastolic BP, mm Hg & 73.4 & 9.4 & 89.2 & 11.3 & $<0.001$ \\
\hline Untreated hypertension: systolic BP, mm Hg & 152.3 & 13.1 & 146.0 & 14.9 & 0.003 \\
\hline Untreated hypertension: diastolic BP, mm Hg & 81.2 & 11.1 & 93.5 & 8.5 & $<0.001$ \\
\hline $\mathrm{CVD}^{7}$ & 11.3 & & 4.0 & & $<0.001$ \\
\hline
\end{tabular}

${ }^{1}$ US $\$$ or euros per year.

${ }^{2}$ Includes moderate and vigorous physical activity.

${ }^{3}$ Higher scores indicate higher intake of recommended foods.

${ }^{4}$ Higher scores indicate higher intake of non-recommended foods.

${ }^{5}$ Fasting plasma glucose $\geq 126 \mathrm{mg} / \mathrm{dL}$ or taking anti-diabetic medication.

${ }^{6} \mathrm{Had}$ systolic $\mathrm{BP} \geq 140 \mathrm{mmHg}$ and/or diastolic $\mathrm{BP} \geq 90 \mathrm{mmHg}$ or taking anti-hypertensive medication.

${ }^{7}$ Includes myocardial infarction, coronary artery disease, heart failure, angina pectoris, transient ischemic attack.

to $1.2 \%$ in $2005-2010$ [4]. Over the same time, increases in physical inactivity and obesity, and decreases in fruit and vegetable consumption have been observed [37]. The biggest prevalence differences between the two present studies were observed for the RFS. Poor health for this score in the Central NY sample (34.5\% of participants) was nearly three times higher than in Luxembourg (11.8\% of participants).

The role of physical activity in weight control is well established. While the age-adjusted proportion of participants not engaging in any physical activity was similar in both study sites (10-12\%), the mean time spent engaging in physical activity per week was over two times higher in the Luxembourg site than Central NY, equating to a difference of approximately 6.5 hours per week. Adjusting for BMI, waist circumference and waist/hip ratio in secondary analyses did not change the results (data not shown). This is consistent with data showing that Europeans walk and cycle over two and four times, respectively, the number of kilometres per person per year, than residents of the United States [10]. Furthermore, active transportation via walking or cycling is also more common in Europe than in North America and the lowest estimates of adult obesity are found in countries that rely more upon active transportation and less upon automobiles $[10,11]$. As per intuition, higher rates of walking and cycling as a means of transport have also been associated with a higher percentage of adults meeting the recommended levels of physical activity, as well as lower estimates of diabetes [11]. The infrastructure in Luxembourg supports walking and cycling for daily

Table 2 Multivariate-adjusted means ${ }^{1}$ and SE for total Cardiovascular Health Score and cardiovascular health metrics, MSLS (n= 673) and ORISCAV-LUX $(n=1145)$

\begin{tabular}{|c|c|c|c|c|c|c|}
\hline \multirow[t]{2}{*}{ Cardiovascular Health variable } & \multicolumn{2}{|c|}{ Central New York MSLS } & \multicolumn{2}{|c|}{ Luxembourg ORISCAV-LUX } & \multirow[t]{2}{*}{ Mean difference } & \multirow[t]{2}{*}{ p-value } \\
\hline & M & SE & $M$ & SE & & \\
\hline Total Cardiovascular Health Score, 0-8 & 3.8 & 0.08 & 4.2 & 0.05 & -0.38 & $<0.001$ \\
\hline \multicolumn{7}{|l|}{ Cardiovascular Health metrics } \\
\hline Smoking, no cigarettes per day & 2.3 & 0.34 & 2.3 & 0.21 & -0.04 & 0.93 \\
\hline $\mathrm{BMl}, \mathrm{kg} / \mathrm{m}^{2}$ & 29.9 & 0.26 & 27.0 & 0.17 & 2.89 & $<0.001$ \\
\hline Physical activity, mins/wk ${ }^{2}$ & 358 & 46 & 754 & 26 & -396 & $<0.001$ \\
\hline Total cholesterol, mg/dl & 201.3 & 2.04 & 207.4 & 1.30 & -6.08 & 0.017 \\
\hline Systolic BP, mm Hg & 122.7 & 0.85 & 132.7 & 0.54 & -9.94 & $<0.001$ \\
\hline Diastolic BP, mm Hg & 70.1 & 0.52 & 83.9 & 0.33 & -13.85 & $<0.001$ \\
\hline Fasting blood glucose, mg/dl & 96.1 & 1.03 & 94.7 & 0.65 & 1.37 & 0.29 \\
\hline RFS, $0-18^{3}$ & 8.9 & 0.14 & 10.9 & 0.09 & -2.0 & $<0.001$ \\
\hline non-RFS, $0-13^{4}$ & 3.5 & 0.08 & 3.0 & 0.05 & 0.55 & $<0.001$ \\
\hline
\end{tabular}

\footnotetext{
${ }^{1}$ Adjusted mean values for age, gender, education and income.

${ }^{2}$ Includes moderate and intense physical activity.

${ }^{3}$ Higher scores indicate higher intake of recommended foods.

${ }^{4}$ Higher scores indicate higher intake of non-recommended foods.
} 
Table 3 Age- and gender-standardized proportions of participants in the MSLS $(n=673)$ and ORISCAV-LUX $(n=1145)$, with poor, intermediate and ideal health for each health component, and for the global Cardiovascular Health Score

\begin{tabular}{|c|c|c|c|c|}
\hline Cardiovascular Health component & Definition $^{1}$ & $\begin{array}{c}\text { Central New York } \\
\text { MSLS (\%) }\end{array}$ & $\begin{array}{c}\text { Luxembourg } \\
\text { ORISCAV-LUX (\%) }\end{array}$ & p-value \\
\hline \multicolumn{5}{|l|}{ BMI } \\
\hline Poor & $\geq 30 \mathrm{~kg} / \mathrm{m}^{2}$ & 43.0 & 25.4 & $<0.001$ \\
\hline Intermediate & $25-29.9 \mathrm{~kg} / \mathrm{m}^{2}$ & 34.5 & 35.0 & 0.88 \\
\hline Ideal & $<25 \mathrm{~kg} / \mathrm{m}^{2}$ & 22.5 & 39.6 & $<0.001$ \\
\hline \multicolumn{5}{|l|}{ Smoking } \\
\hline Poor & Current smoker & 16.6 & 18.8 & 0.43 \\
\hline Intermediate & Former smoker, quit $<12$ months & 54.5 & 28.6 & $<0.001$ \\
\hline Ideal & Never or quit $>12$ months & 29.0 & 52.6 & $<0.001$ \\
\hline \multicolumn{5}{|l|}{ Physical activity } \\
\hline Poor & No physical activity & 10.6 & 11.9 & 0.58 \\
\hline Intermediate & 1-149 min/wk moderate intensity activity ${ }^{2}$ & 30.0 & 19.8 & 0.001 \\
\hline Ideal & $\geq 150 \mathrm{~min} / \mathrm{wk}$ moderate intensity activity ${ }^{3}$ & 59.5 & 68.3 & 0.013 \\
\hline \multicolumn{5}{|l|}{ Fasting plasma glucose } \\
\hline Poor & $\geq 126 \mathrm{mg} / \mathrm{dL}$ & 5.6 & 4.8 & 0.48 \\
\hline Intermediate & $100-125 \mathrm{mg} / \mathrm{dL}$ or treated to goal & 15.4 & 21.4 & 0.021 \\
\hline Ideal & $<100 \mathrm{mg} / \mathrm{dL}$ & 79.0 & 73.8 & 0.056 \\
\hline \multicolumn{5}{|l|}{ Total cholesterol } \\
\hline Poor & $\geq 240 \mathrm{mg} / \mathrm{dL}$ & 11.6 & 19.6 & $<0.001$ \\
\hline Intermediate & $200-239 \mathrm{mg} / \mathrm{dL}$ or treated to goal & 37.4 & 33.5 & 0.20 \\
\hline Ideal & $<200 \mathrm{mg} / \mathrm{dL}$ & 51.0 & 46.9 & 0.21 \\
\hline \multicolumn{5}{|l|}{ Blood pressure } \\
\hline Poor & Systolic BP $\geq 140$ or diastolic BP $\geq 90 \mathrm{~mm} \mathrm{Hg}$ & 18.4 & 38.5 & $<0.001$ \\
\hline Intermediate & $\begin{array}{l}\text { Systolic BP } 120-139 \text { or diastolic BP } 80-80 \mathrm{~mm} \mathrm{Hg} \\
\text { or treated to goal }\end{array}$ & 33.0 & 38.6 & 0.10 \\
\hline Ideal & $<120 / 80 \mathrm{~mm} \mathrm{Hg}$ & 48.6 & 23.0 & $<0.001$ \\
\hline \multicolumn{5}{|l|}{$\mathrm{RFS}^{4}$} \\
\hline Poor & $0-7$ & 34.5 & 11.8 & $<0.001$ \\
\hline Intermediate & $8-11$ & 48.8 & 45.5 & 0.34 \\
\hline Ideal & $12-18$ & 16.7 & 42.8 & $<0.001$ \\
\hline \multicolumn{5}{|l|}{ non-RFS ${ }^{5}$} \\
\hline Poor & $5-13$ & 24.9 & 18.4 & 0.047 \\
\hline Intermediate & $3-4$ & 45.5 & 42.7 & 0.41 \\
\hline Ideal & $0-2$ & 29.6 & 38.9 & 0.005 \\
\hline \multicolumn{5}{|l|}{ Global CHS } \\
\hline Low & $0-2$ components in ideal range & 19.6 & 15.2 & 0.12 \\
\hline Medium & 3-5 components in ideal range & 65.2 & 64.1 & 0.76 \\
\hline High & 6-8 components in ideal range & 15.2 & 20.6 & 0.049 \\
\hline
\end{tabular}

${ }^{1}$ Definitions according to the American Heart Association except for diet score, for adults $>20$ years of age.

${ }^{2}$ Or $1-74 \mathrm{~min} / \mathrm{wk}$ vigorous intensity activity.

${ }^{3} \mathrm{Or} \geq 75 \mathrm{~min} / \mathrm{wk}$ vigorous intensity activity.

${ }^{4}$ RFS scored out of 18 , with higher scores indicating a higher consumption of recommended foods to increase.

${ }^{5}$ non-RFS scored out of 13 , with higher scores indicating a higher consumption of foods recommended to reduce.

travel and may be one contributing factor that explains the difference observed in the present study. During the period of data collection for MSLS, the automobile was the predominant mode of transportation in Syracuse and Central New York with few cycling paths on city and town streets. 


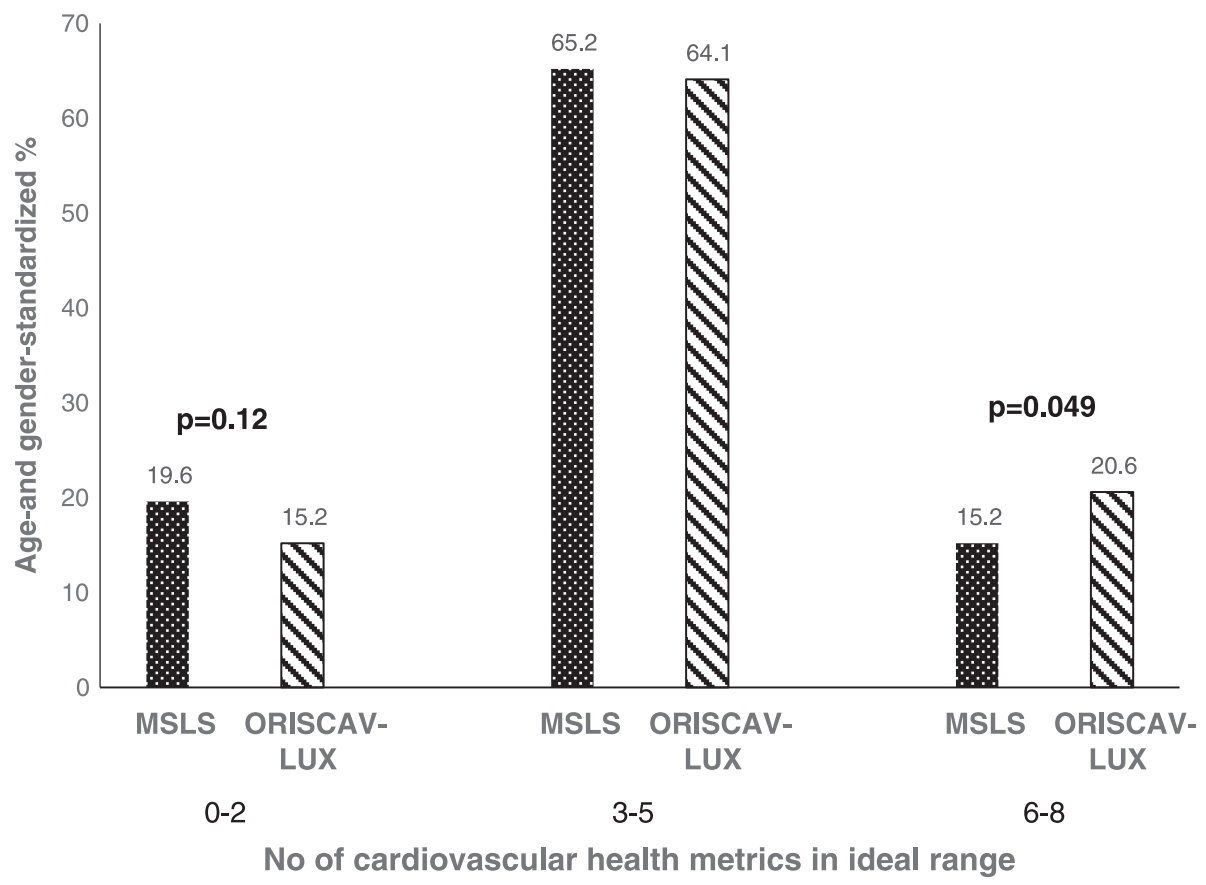

Figure 1 Proportion of Maine-Syracuse Longitudinal Study (MSLS) and Observation of Cardiovascular Risk Factors in Luxembourg (ORISCAV-LUX) participants (aged 30-69 years) with low (0-2 health components at ideal levels), medium (3-5 health components at ideal levels), and high (6-8 health components at ideal levels) Cardiovascular Health Score. p-values represent significant differences in proportions between the 2 sites.

In contrast to these findings, average age and genderadjusted BP was $133 / 84 \mathrm{mmHg}$ in the Luxembourg sample compared with $123 / 70 \mathrm{mmHg}$ in the Central NY sample. Epidemiological research utilizing national survey data from six European countries, the US and Canada, also found higher BP levels in Europe, and reported very similar levels to those in the present study: $136 / 83 \mathrm{mmHg}$ in Europe and $127 / 77 \mathrm{mmHg}$ in North America [38]. Of note, less than $40 \%$ of those with diagnosed hypertension in the Luxembourg sample were being treated for high BP, compared with nearly $85 \%$ in the MSLS. Although hypertension has the same classification in the US and Europe (systolic BP $\geq 140 \mathrm{mmHg}$ and/or diastolic BP $\geq 90 \mathrm{mmHg}$ ) [39,40], the initial approaches to $\mathrm{BP}$ control vary and we can only speculate that this may contribute to the BP differences observed $[39,40]$. Lifestyle modification and immediate initiation of antihypertensive drug therapy is recommended in the US [40], whereas in Europe, the immediate initiation of drugs needs the presence of other symptomatic CVD risk factors [39].

In addition, poor awareness of relatively 'silent', asymptomatic cardiovascular risk factors including hypertension and dyslipidemia has been demonstrated in this Luxembourg population, with $60 \%$ unaware of their diagnosed hypertension (diagnosis made from the
ORISCAV-LUX survey) [41]. This level of unawareness is two-fold that of the US; national estimates from the National Health and Nutrition Examination Survey 19992000 data indicate an unawareness level of 30\% [40].

There are several study limitations. ORISCAV-LUX was a community, national population-based study, whereas MSLS was a community-based sample restricted to Central NY. The MSLS sample is not nationally representative, but both Luxembourg and the Syracuse metropolitan statistical area (MSA) have similar population sizes of slightly more than half a million inhabitants. In 2008, Central NY state had an almost identical age-adjusted CVD mortality estimate as the US (244.0 versus 244.8 per 100,000 deaths $[42,43]$. In Onondanga County, NY, CVD mortality estimates have been decreasing, following a national trend $[42,43]$. While African Americans have been found to have significantly fewer ideal cardiovascular health components than whites [3,5], a sensitivity analysis excluding African Americans (9.7\% in MSLS) did not affect the pattern of results. Smoking, diet and physical activity data were based on participant self-report and the same instruments were not used in both studies.

There are several study strengths. This is the first study to compare three levels of cardiovascular health in two studies from two different countries. We are not aware of published data using ideal cardiovascular health 
in countries outside of the USA. To compare prevalence estimates across these two samples with different age compositions, the effects of variation in age structure were removed by using a 'world' standard population to standardize age [34]. The prevalence differences observed in these analyses were confirmed when comparisons between the two sites were made using the health metrics as continuous variables, with the added control of education and income.

The purpose of our study was solely to describe the epidemiological patterns of cardiovascular health in these two study sites. The contrasts found are of substantial magnitude, however the findings neither provide causal explanations nor effectiveness data on the health care system in either region.

\section{Conclusions}

The main finding of note in the present study is in the recognition that the majority of participants at both study sites had overall cardiovascular health scores that fell within the intermediate range, but the overall $\mathrm{CHS}$ was higher in Luxembourg. The differences found for the BP, diet, and physical activity metrics are particularly notable. As both Luxembourg and the New York State Department of Health have implemented public health policies to promote and maintain population cardiovascular health $[44,45]$, it is difficult to attribute findings to specific health care policies, particularly as health care delivery is different in each region.

However the current findings suggest that different strategies for intervention will be important for different countries and underscore the need for cross-national comparisons. The continued improvement of education programs and focus on prevention measures may be helpful in both countries. Infrastructure to support active means of transportation may be an important consideration. Regardless of the approaches taken to achieve CVD reduction, even small health behavior changes at a population level would produce relatively large increases in the proportion of individuals in both ideal and intermediate categories [1]. In a similar vain, small reductions in weight gain over decades may accumulate into meaningful reductions in risk for obesity-related disorders [46]. The impact on US mortality from poor dietary habits is significant [47], yet simple changes, such as dietary reduction of $3 \mathrm{~g}$ of salt per day, is projected to yield substantial reductions in mortality and health care costs [48]. For example, the total costs of diagnosed diabetes in the US was estimated at \$245 billion in 2012 [49], and costs approximately $€ 148$ million per year in Luxembourg [50]. Early intervention strategies to increasing physical activity, make healthier food choices, cease smoking, and lower blood sugar levels all seem important based on our findings, and may help to produce significant savings in health care costs in the long term. It may be particularly important for future studies to focus on children and young adults [51] in relation to interventions designed to raise the AHA cardiovascular health metrics to higher levels.

\section{Abbreviations}

AHA: American Heart Association; BMI: Body mass index; CHS: Cardiovascular Health Score; CRP: C-reactive protein; CVD: Cardiovascular disease; FFQ: Food frequency questionnaire; IPAQ: International Physical Activity Questionnaire: MSLS: Maine-Syracuse Longitudinal Study; non-RFS: non-Recommended Food Score; NY: New York; ORISCAV-LUX: Observation of Cardiovascular Risk Factors in Luxembourg; RFS: Recommended Food Score.

\section{Competing interests}

The authors declare that they have no competing interests.

\section{Authors' contributions}

GC: conceptualization of the present study, data analyses and interpretation, manuscript drafting. ME: MSLS chief investigator, manuscript drafting and revision. NS: statistical analyses and interpretation, critical review of manuscript. AD: critical review and drafting of manuscript. JB, CD: ORISCAV-LUX investigators, critical review of manuscript. AA: ORISCAV-LUX investigator, study design, data analyses and interpretation, critical review of manuscript. All authors read and approved the final manuscript.

\section{Acknowledgments}

This work was supported by the National Heart, Lung and Blood Institute, National Institutes of Health (Grants R01HL067358, R01HL081290 to the University of Maine); by the National Institute on Aging, National Institutes of Health (Grant R01AG03055 to the University of Maine); by the National Institute of Health (Grants R01HD069769, R21CA158877, R01AG13180, R01CA158361 to AD); by United States Department of Agriculture (Grants PENR-2010-04643, PENR-2011-04489 to AD); by the National Health and Medical Research Council Sidney Sax Research Fellowship (Australia) (Grant GNT1054567 to GC); by Fond National de Rechcerche (FNR Luxembourg, for DIQUA-LUX project).

\section{Author details}

1 Nutritional Physiology Research Centre, University of South Australia, Adelaide, Australia. ${ }^{2}$ Centre de Recherche Public Santé, Centre d'Etudes en Santé, Strassen, Grand-Duchy of Luxembourg. ${ }^{3}$ Department of Psychology, University of Maine, Orono, ME, USA. ${ }^{4}$ Graduate School of Biomedical Sciences and Engineering, University of Maine, Orono, ME, USA. ${ }^{5}$ Department of Public Health, Temple University, Philadelphia, PA, USA. ${ }^{6}$ Service de Cardiologie, Centre Hospitalier du Luxembourg, Luxembourg, Grand-Duchy of Luxembourg.

Received: 29 October 2013 Accepted: 10 March 2014

Published: 15 March 2014

\section{References}

1. Go AS, Mozaffarian D, Roger VL, Benjamin EJ, Berry JD, Borden WB, Bravata DM, Dai SF, Ford ES, Fox CS, Franco S, Fullerton HJ, Gillespie C, Hailpern SM, Heit JA, Howard VJ, Huffman MD, Kissela BM, Kittner SJ, Lackland DT, Lichtman JH, Lisabeth LD, Magid D, Marcus GM, Marelli A, Matchar DB, McGuire DK, Mohler ER, Moy CS, Mussolino ME, et al: Heart Disease and stroke statistics-2013 update a report from the American Heart Association. Circulation 2013, 127(1):E6-E245.

2. Lloyd-Jones DM, Hong Y, Labarthe D, Mozaffarian D, Appel LJ, Van Horn L, Greenlund K, Daniels S, Nichol G, Tomaselli GF, Arnett DK, Fonarow GC, Ho PM, Lauer MS, Masoudi FA, Robertson RM, Roger V, Schwamm LH, Sorlie P, Yancy CW, Rosamond WD, American Heart Association Strategic Planning Task Force and Statistics Committee: Defining and setting national goals for cardiovascular health promotion and disease reduction: the American Heart Association's strategic Impact Goal through 2020 and beyond. Circulation 2010, 121(4):586-613.

3. Bambs C, Kip KE, Dinga A, Mulukutla SR, Aiyer AN, Reis SE: Low prevalence of "ideal cardiovascular health" in a community-based population the heart Strategies Concentrating on Risk Evaluation (Heart SCORE) study. Circulation 2011, 123(8):850-857. 
4. Yang $\mathrm{QH}$, Cogswell ME, Flanders WD, Hong $Y L$, Zhang ZF, Loustalot $F$, Gillespie C, Merritt R, Hu FB: Trends in cardiovascular health metrics and associations with all-cause and CVD mortality among US adults. JAMA 2012, 307(12):1273-1283.

5. Folsom AR, Yatsuya H, Nettleton JA, Lutsey PL, Cushman M, Rosamond WD, Investigators AS: Community prevalence of ideal cardiovascular health, by the American Heart Association definition, and relationship with cardiovascular disease incidence. J Am Coll Cardiol 2011, 57(16):1690-1696.

6. Ford ES, Greenlund KJ, Hong YL: Ideal cardiovascular health and mortality from all causes and diseases of the circulatory system among adults in the United States. Circulation 2012, 125(8):987-995.

7. Dong CH, Rundek T, Wright CB, Anwar Z, Elkind MSV, Sacco RL: Ideal cardiovascular health predicts lower risks of myocardial infarction, stroke, and vascular death across whites, blacks, and hispanics the Northern Manhattan study. Circulation 2012, 125(24):2975-2984.

8. Wu SL, Huang ZR, Yang XC, Zhou Y, Wang AX, Chen L, Zhao HY, Ruan CY, Wu YT, Xin AJ, Li K, Jin C, Cai J: Prevalence of ideal cardiovascular health and its relationship with the 4-year cardiovascular events in a northern Chinese industrial city. Circ Cardiovasc Qual Outcomes 2012, 5(4):487-493.

9. Directorate of Health Ministry of Health Luxembourg: National Statistics of all causes of death, Statistiques des causes de décès pour l'année. 2011.

10. Bassett DR, Pucher J, Buehler R, Thompson DL, Crouter SE: Walking, cycling, and obesity rates in Europe, North America, and Australia. JPAH 2008, 5(6):795-814.

11. Pucher J, Buehler R, Bassett DR, Dannenberg AL: Walking and cycling to health: a comparative analysis of city, state, and international data. Am J Public Health 2010, 100(10):1986-1992.

12. Frank LD, Andresen MA, Schmid TL: Obesity relationships with community design, physical activity, and time spent in cars. Am J Prev Med 2004, 27(2):87-96.

13. Lindstrom M: Means of transportation to work and overweight and obesity: a population-based study in southern Sweden. Prev Med 2008, 46(1):22-28

14. Wen LM, Rissel C: Inverse associations between cycling to work, public transport, and overweight and obesity: Findings from a population based study in Australia. Prev Med 2008, 46(1):29-32.

15. Gordon-Larsen P, Boone-Heinonen J, Sidney S, Sternfeld B, Jacobs DR, Lewis CE: Active commuting and cardiovascular disease risk the CARDIA study. Arch Intern Med 2009, 169(13):1216-1223.

16. Dore GA, Elias MF, Robbins MA, Budge MM, Elias PK: Relation between central adiposity and cognitive function in the Maine-Syracuse Study: attenuation by physical activity. Ann Behav Med 2008, 35(3):341-350.

17. Elias MF, Robbins MA, Budge MM, Abhayaratna WP, Dore GA, Elias PK: Arterial pulse wave velocity and cognition with advancing age. Hypertension 2009, 53(4):668-673.

18. Elias MF, Robbins MA, Budge MM, Elias PK, Brennan SL, Johnston C, Nagy Z, Bates CJ: Homocysteine, folate, and vitamins B6 and B12 blood levels in relation to cognitive performance: the Maine-Syracuse study. Psychosom Med 2006, 68(4):547-554

19. Robbins MA, Elias MF, Elias PK, Budge MM: Blood pressure and cognitive function in an African-American and a Caucasian-American sample: the Maine-Syracuse Study. Psychosom Med 2005, 67(5):707-714.

20. County Health Indicator Profiles (2005-2009). [http://www.health.ny.gov]

21. Alkerwi A, Sauvageot N, Donneau AF, Lair ML, Couffignal S, Beissel J, Delagardelle C, Wagener Y, Albert A, Guillaume M: First nationwide survey on cardiovascular risk factors in Grand-Duchy of Luxembourg (ORISCAV-LUX). BMC Public Health 2010, 10:468.

22. Alkerwi A, Sauvageot N, Couffignal S, Albert A, Lair ML, Guillaume M: Comparison of participants and non-participants to the ORISCAV-LUX population-based study on cardiovascular risk factors in Luxembourg. BMC Med Res Methodol 2010, 10:80

23. Alkerwi A, Donneau AF, Sauvageot N, Lair ML, Scheen A, Albert A Guillaume M: Prevalence of the metabolic syndrome in Luxembourg according to the Joint Interim Statement definition estimated from the ORISCAV-LUX study. BMC Public Health 2011, 11(1):4.

24. Wolf AM, Hunter DJ, Colditz GA, Manson JE, Stampfer MJ, Corsano KA, Rosner B, Kriska A, Willett WC: Reproducibility and validity of a self-administered physical-activity quesionnaire. Int J Epidemio/ 1994, 23(5):991-999.

25. Kroke A, Klipstein-Grobusch K, Voss S, Moseneder J, Thielecke F, Noack R, Boeing $\mathrm{H}$ : Validation of a self-administered food-frequency questionnaire administered in the European Prospective Investigation into Cancer and
Nutrition (EPIC) Study: comparison of energy, protein, and macronutuient intakes estimated with the doubly labeled water, urinary nitrogen, and repeated 24-h dietary recall methods. Am J Clin Nutr 1999, 70(4):439-447.

26. International Physical Activity Questionnaire (2005). [http://www.ipaq.ki. se/ipaq.htm]

27. Sauvageot N, Alkerwi A, Albert A, Guillaume M: Use of food frequency questionnaire to assess relationships between dietary habits and cardiovascular risk factors in NESCAV study: validation with biomarkers. Nutr J 2013, 12(1):143.

28. Kant AK, Schatzkin A, Graubard Bl, Schairer C: A prospective study of diet quality and mortality in women. JAMA 2000, 283(16):2109-2115.

29. Michels KB, Wolk A: A prospective study of variety of healthy foods and mortality in women. Int J Epidemiol 2002, 31(4):847-854.

30. US Department of Agriculture and US Department of Health and Human Services: Dietary Guidelines for Americans 2010. 7th edition. Washington, D.C: U.S. Government Printing Office; 2010.

31. Kaluza J, Hakansson N, Brzozowska A, Wolk A: Diet quality and mortality: a population-based prospective study of men. Eur J Clin Nutr 2009, 63(4):451-457

32. Ahmed HM, Blaha MJ, Nasir K, Jones SR, Rivera JJ, Agatston A, Blankstein R, Wong ND, Lakoski S, Budoff MJ, Burke GL, Sibley CT, Ouyang P, Blumenthal RS: Low-risk lifestyle, coronary calcium, cardiovascular events, and mortality: results from MESA. Am J Epidemio/ 2013, 178(1):12-21.

33. Wengreen $\mathrm{HJ}$, Neilson C, Munger R, Corcoran C: Diet quality is associated with better cognitive test performance among aging men and women. J Nutr 2009, 139(10):1944-1949.

34. Age standardization of rates: a new WHO standard. [http://www.who.int/ healthinfo/paper31.pdf]

35. Segi M: Cancer Mortality for Selected Sites in 24 Countries (1950-57). Sendai, Japan: Department of Public Health, Tohoku University of Medicine; 1960.

36. Breslow NE, Day NE: Statistical Methods in Cancer Research - Volume II - The Design and Analysis of Cohort Studies: IARC Scientific Publications No. 82. New York, USA: Oxford University Press; 1987.

37. King DE, Mainous AG 3rd, Carnemolla M, Everett CJ: Adherence to healthy lifestyle habits in US adults, 1988-2006. Am J Med 2009, 122(6):528-534.

38. Wolf-Maier K, Cooper RS, Banegas JR, Giampaoli S, Hense HW, Joffres M, Kastarinen M, Poulter N, Primatesta P, Rodriguez-Artalejo F, Stegmayr B, Thamm M, Tuomilehto J, Vanuzzo D, Vescio F: Hypertension, prevalence and blood pressure levels in 6 European countries, Canada, and the United States. JAMA 2003, 289(18):2363-2369.

39. Mancia G, Fagard R, Narkiewicz K, Redon J, Zanchetti A, Bohm M, Christiaens T, Cifkova R, De Backer G, Dominiczak A, Galderisi M, Grobbee DE, Jaarsma T, Kirchhof P, Kjeldsen SE, Laurent S, Manolis AJ, Nilsson PM, Ruilope LM, Schmieder RE, Sirnes PA, Sleight P, Viigimaa M, Waeber B, Zannad F, Task Force M embers: 2013 ESH/ESC Guidelines for the management of arterial hypertension. Eur Heart J 2013, 34(28):2159-+

40. The seventh report of the Joint National Committee on prevention detection, evaluation, and treatment of high blood pressure. JNC 7 Express [http://www.nhlbi.nih.gov/guidelines/hypertension/express.pdf]

41. Alkerwi A, Pagny S, Lair ML, Delagardelle C, Beissel J: Level of unawareness and management of diabetes, hypertension, and dyslipidemia among adults in Luxembourg: findings from ORISCAV-LUX study. PLoS One 2013, 8(3):e57920.

42. Cardiovascular disease deaths and death rates. [http://www.health.ny.gov]

43. Morbidity \& mortality: 2007 chart book on cardiovascular, lung, and blood diseases. [http://www.health.ny.gov/statistics/environmental/ public_health_tracking/health/heart.htm]

44. Vers un plan national alimentation saine et activité physique (PNS 2006-2012). [http://www.sante.public.lu]

45. Heart disease and stroke: New York State. [http://www.health.ny.gov/ statistics/environmental/public_health_tracking/health/heart.htm]

46. DiPietro L: Physical activity in the prevention of obesity: current evidence and research issues. Med Sci Sports Exerc 1999, 31(11):S542-S546.

47. Danaei G, Ding EL, Mozaffarian D, Taylor B, Rehm J, Murray CJL, Ezzati M: The preventable causes of death in the United States: comparative risk assessment of dietary, lifestyle, and metabolic risk factors. PLoS Med 2009, 6(4):e1000058.

48. Bibbins-Domingo K, Chertow GM, Coxson PG, Moran A, Lightwood JM, Pletcher MJ, Goldman L: Projected effect of dietary salt reductions on future cardiovascular disease. N Engl J Med 2010, 362(7):590-599.

49. The cost of diabetes. [http://www.diabetes.org/advocacy/news-events/costof-diabetes.html] 
50. International Diabetes Federation: IDF Diabetes Atlas. 4th edition. Brussels, Belgium: International Diabetes Federation; 2009.

51. Laitinen TT, Pahkala K, Magnussen CG, Viikari JSA, Oikonen M, Taittonen L, Mikkila V, Jokinen E, Hutri-Kahonen N, Laitinen T, Kahonen M, Lehtimaki T, Raitakari OT, Juonala M: Ideal cardiovascular health in childhood and cardiometabolic outcomes in adulthood the cardiovascular risk in Young Finns study. Circulation 2012, 125(16):1971-1978.

doi:10.1186/1471-2458-14-253

Cite this article as: Crichton et al:: Cardiovascular health: a cross-national comparison between the Maine Syracuse Study (Central New York, USA) and ORISCAV-LUX (Luxembourg). BMC Public Health 2014 14:253.

\section{Submit your next manuscript to BioMed Central and take full advantage of:}

- Convenient online submission

- Thorough peer review

- No space constraints or color figure charges

- Immediate publication on acceptance

- Inclusion in PubMed, CAS, Scopus and Google Scholar

- Research which is freely available for redistribution 